International Journal of Theoretical and Applied Finance

Vol. 3, No. 1 (2000) 85-100

(C) World Scientific Publishing Company

\title{
MARKET SEGMENTATION AND NOISE TRADER RISK
}

\author{
VIHANG ERRUNZA \\ McGill University, Montreal, Canada \\ KED HOGAN \\ Barclays Global Investors, San Francisco, USA \\ MAO-WEI HUNG \\ Department of International Business, College of Management, \\ National Taiwan University, No. 1, Section 4, Roosevelt Road, Taipei, Taiwan \\ E-mail: hung@handel.mba.ntu.edu.tw
}

Received 16 April 1999

\begin{abstract}
A simple asset pricing model is developed to take into account two important characteristics in global investments: market segmentation and noise trader risk. Our results show the removal of international investment barriers and cross-border listings have not led to a fully integrated international capital market. We also show that different degree of investor rationality across borders induces an additional component of risk premium which is related to the "noise spill-over effect".
\end{abstract}

Keywords: Asset pricing, market segmentation, noise trader.

\section{Introduction}

Global capital market segmentation has been the focus of a significant body of international asset pricing literature. For example, Stulz [9], Errunza and Losq [4], Eun and Janakiramanan [6], Padmanabhan [8] and Basak [1] have shown that obstacles to free flow of capital will in general lead to an additional risk premium on securities that are not freely accessible. Over the past decade, many types of investment barriers that limiting foreign capital flows to emerging markets have been removed. Bekaert and Harvey [2] present evidence which suggests that the transition from segmentation to integration has been anything but smooth. Despite the removal of investment barriers and significant cross-border listings, substantial market segmentation remains.

It is also widely believed that investors may differ in terms of investment horizon and their abilities to price securities rationally and thus induce an additional component of risk premium. DeLong, Shleifer, Summers, and Waldmann (DSSW) [3] argue that under irrational price behavior and finite investment horizon, irrational noise traders will induce a risk premium in security prices. In the context of U.S. 
markets, the introduction of noise, may explain well-known anomalies, for example, the closed-end fund discount puzzle.

In this paper we incorporate noise into an international asset pricing model with one-way investment barrier. The added dimension of noise allows us to consider possible causes for the persistence of market segmentation despite significant steps toward globalization. Furthermore, the necessary condition of finite investment horizon appears to be a more widely held belief for cross-border investors than perhaps for domestic investors.

Indeed, our model suggests that the removal of investment barriers and crosslistings are not sufficient for achieving full integration in the presence of noise traders. Although the one-way barrier leads to some integration in contrast to two-way barriers, it does not shield emerging markets from the effect of noise spillover from developed markets. Thus, policies that reduce noise and encourage long horizon investing are necessary to obtain full benefits of liberalization aimed at global risk sharing.

Our paper is organized as follows. Section 2 describes the model setup. Steady state equilibrium asset prices are presented in Sec. 3. Section 4 discusses the noise trader risk and Sec. 5 concludes the paper.

\section{Model}

We adopt the two-period overlapping generations framework of DSSW in which investors' first period endowment is exogenously determined, no labor decisions are made, and at the end of second period, all assets are liquidated to the "next generation" and the proceeds used for consumption by the old generation. The salient feature of the model which introduces noise to be priced is that the investment horizon is sufficiently short so as to not outlive irrational pricing or noise effects.

There are two countries, domestic $(D)$ and foreign $(F)$, in which two types of risky securities are traded. We assume each country has only two securities: one for each type. ${ }^{\text {a }}$ Asset type " $a$ " is priced absent of noise. Asset type " $b$ " is priced with noise. There is a risk-free security across both countries with a constant rate of return, $r$. Asset supplies are fixed and normalized to be one. Security prices are assumed to have a joint normal distribution and foreign exchange risk is assumed not to exist.

Investors are either rational or noise traders. Investors type $i(\in I)$ are rational domestic investors, type $n(\in N)$ are domestic noise traders. Similarly, investors type $j(\in J)$ are rational foreign investors, type $k(\in K)$ are foreign noise traders. All investors have absolute risk aversion utility with possibly different Arrow-Pratt risk aversion coefficients: $U(W)=-\exp (-2 \alpha W)$, where $\alpha$ is the Arrow-Pratt

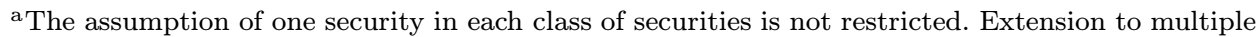
securities in each class is straightforward.
} 
absolute risk aversion coefficient, $W$ is the end of period wealth and exp is the exponential function.

In order to facilitate our discussion, we adopt the following notations:

- $P_{t}^{d a} \equiv$ price for the domestic security without noise at time $t$.

- $P_{t}^{d b} \equiv$ price for the domestic security with noise at time $t$.

- $P_{t}^{f a} \equiv$ price for the foreign security without noise at time $t$.

- $P_{t}^{f b} \equiv$ price for the foreign security with noise at time $t$.

- $C_{t}(l, m) \equiv \operatorname{Cov}_{t}\left(p_{t+1}^{j}, p_{t+1}^{k}\right), l, m \in(d a, d b, f a, f b)$

- $\Omega_{2 t} \equiv$ domestic security variance - covariance matrix

$$
\equiv\left[\begin{array}{ll}
C_{t}(d a, d a) & C_{t}(d a, d b) \\
C_{t}(d b, d a) & C_{t}(d b, d b)
\end{array}\right]
$$

- $\Omega_{4 t} \equiv$ global security variance - covariance matrix

$$
\equiv\left[\begin{array}{cccc}
C_{t}(d a, d a) & C_{t}(d a, d b) & C_{t}(d a, f a) & C_{t}(d a, f b) \\
C_{t}(d b, d a) & C_{t}(d b, d b) & C_{t}(d b, f a) & C_{t}(d b, f b) \\
C_{t}(f a, d a) & C_{t}(f a, d b) & C_{t}(f a, f a) & C_{t}(f a, f b) \\
C_{t}(f b, d a) & C_{t}(f b, d b) & C_{t}(f b, f a) & C_{t}(f b, f b)
\end{array}\right] .
$$

There are mainly three types of international capital market structure analyzed in the literature: full integration, segmentation and mild segmentation. In the paper, we focus on a mildly segmented market which prohibits domestic investors from investing in foreign assets while foreign investors have access to both foreign and domestic assets. Note that polar cases of integration and segmentation are just special cases of our model. In such a setting, domestic investors face the following budget constraint when choosing their portfolios:

$$
W_{t+1}=\lambda_{t}^{s, d a}\left(p_{t+1}^{d a}\right)+\lambda_{t}^{s, d b}\left(p_{t+1}^{d b}\right)+(1+r)\left(W_{t}-\lambda_{t}^{s, d a} p_{t}^{d a}-\lambda_{t}^{s, d b} p_{t}^{d b}\right),
$$

where $\lambda^{s, L}$ are the demand function of investor type $s \in(I \& N)$ for security $L \in$ $(d a, d b)$ and $W_{t}$ is the investor's wealth at time $t$.

Foreign investors without restricted investment opportunities, face the following budget constraint:

$$
\begin{aligned}
W_{t+1}= & \lambda_{t}^{s, d a}\left(p_{t+1}^{d a}\right)+\lambda_{t}^{s, d b}\left(p_{t+1}^{d b}\right)+\lambda_{t}^{s, f a}\left(p_{t+1}^{f a}\right)+\lambda_{t}^{s, f b}\left(p_{t+1}^{f b}\right) \\
& +(1+r)\left(W_{t}-\lambda_{t}^{s, d a} p_{t}^{d a}-\lambda_{t}^{s, d b} p_{t}^{d b}-\lambda_{t}^{s, f a} p_{t}^{f a}-\lambda_{t}^{s, f b} p_{t}^{f b}\right),
\end{aligned}
$$

where $\lambda^{s, L}$ are the demand function of investor type $s \in(J \& K)$ for security $L \in(d a, d b, f a, f b)$. 
Given exponential utility functions and assuming risky securities are jointly normal, expected utility can be equivalently expressed as

$$
E_{t}\left(U_{t}\right)=E_{t}\left(W_{t+1}\right)-\alpha \cdot \operatorname{Var}_{t}\left(W_{t+1}\right)
$$

where $E_{t}$ and $\operatorname{Var}_{t}$ are conditional expectation and conditional variance, respectively.

This implies that rational investors $i \in I$ determine asset demands by maximizing the following expression:

$$
\begin{aligned}
E_{t}\left(U_{t}^{i}\right)= & {\left[\begin{array}{l}
\lambda_{t}^{i, d a} \\
\lambda_{t}^{i, d b}
\end{array}\right]^{\prime}\left[\begin{array}{l}
E_{t}\left(p_{t+1}^{d a}\right)-p_{t}^{d a}(1+r) \\
E_{t}\left(p_{t+1}^{d b}\right)-p_{t}^{d b}(1+r)
\end{array}\right] } \\
& +W_{t}(1+r)-\alpha^{i}\left[\begin{array}{l}
\lambda_{t}^{i, d a} \\
\lambda_{t}^{i, d b}
\end{array}\right]^{\prime} \Omega_{2 t}\left[\begin{array}{l}
\lambda_{t}^{i, d a} \\
\lambda_{t}^{i, d b}
\end{array}\right]
\end{aligned}
$$

and foreign rational investors $j \in J$ maximize

$$
\begin{aligned}
E_{t}\left(U_{t}^{j}\right)= & {\left[\begin{array}{c}
\lambda_{t}^{j, d a} \\
\lambda_{t}^{j, d b} \\
\lambda_{t}^{j, f a} \\
\lambda_{t}^{j, f b}
\end{array}\right]^{\prime}\left[\begin{array}{c}
E_{t}\left(p_{t+1}^{d a}\right)-p_{t}^{d a}(1+r) \\
E_{t}\left(p_{t+1}^{d b}\right)-p_{t}^{d b}(1+r) \\
E_{t}\left(p_{t+1}^{f a}\right)-p_{t}^{f a}(1+r) \\
E_{t}\left(p_{t+1}^{f b}\right)-p_{t}^{f b}(1+r)
\end{array}\right] } \\
& +W_{t}(1+r)-\alpha^{j}\left[\begin{array}{c}
\lambda_{t}^{i, d a} \\
\lambda_{t}^{i, d b} \\
\lambda_{t}^{i, f a} \\
\lambda_{t}^{i, f b}
\end{array}\right] \Omega_{4 t}\left[\begin{array}{l}
\lambda_{t}^{i, d a} \\
\lambda_{t}^{i, d b} \\
\lambda_{t}^{i, f a} \\
\lambda_{t}^{i, f b}
\end{array}\right] .
\end{aligned}
$$

We further assume that noise traders misperceive the expected price of $p_{t+1}^{d b}$ and $p_{t+1}^{f b}$, by random noise factors $\rho_{t}^{D}$ and $\rho_{t}^{F}$, respectively.

Hence, domestic noise traders $n \in N$ determine asset demands by maximizing

$$
\begin{aligned}
E_{t}\left(U_{t}^{n}\right)= & {\left[\begin{array}{c}
\lambda_{t}^{n, d a} \\
\lambda_{t}^{n, d b}
\end{array}\right]^{\prime}\left[\begin{array}{l}
E_{t}\left(p_{t+1}^{d a}\right)-p_{t}^{d a}(1+r) \\
E_{t}\left(p_{t+1}^{d b}\right)-\rho_{t}^{D}-p_{t}^{d b}(1+r)
\end{array}\right] } \\
& +W_{t}(1+r)-\alpha^{n}\left[\begin{array}{c}
\lambda_{t}^{n, d a} \\
\lambda_{t}^{n, d b}
\end{array}\right]^{\prime} \Omega_{2 t}\left[\begin{array}{l}
\lambda_{t}^{n, d a} \\
\lambda_{t}^{n, d b}
\end{array}\right]
\end{aligned}
$$


and foreign noise traders $k \in K$ determine asset demands by maximizing ${ }^{\mathrm{b}}$

$$
\begin{aligned}
E_{t}\left(U_{t}^{k}\right)= & {\left[\begin{array}{l}
\lambda_{t}^{k, d a} \\
\lambda_{t}^{k, d b} \\
\lambda_{t}^{j k f a} \\
\lambda_{t}^{k, f b}
\end{array}\right]^{\prime}\left[\begin{array}{l}
E_{t}\left(p_{t+1}^{d a}\right)-p_{t}^{d a}(1+r) \\
E_{t}\left(p_{t+1}^{d b}\right)-\rho_{t}^{D}-p_{t}^{d b}(1+r) \\
E_{t}\left(p_{t+1}^{f a}\right)-p_{t}^{f a}(1+r) \\
E_{t}\left(p_{t+1}^{f b}\right)-\rho_{t}^{F}-p_{t}^{f b}(1+r)
\end{array}\right] } \\
& +W_{t}(1+r)-\alpha^{k}\left[\begin{array}{c}
\lambda_{t}^{k, d a} \\
\lambda_{t}^{k, d b} \\
\lambda_{t}^{k, f a} \\
\lambda_{t}^{k, f b}
\end{array}\right] \Omega_{4 t}^{\prime}\left[\begin{array}{l}
\lambda_{t}^{k, d a} \\
\lambda_{t}^{k, d b} \\
\lambda_{t}^{k, f a} \\
\lambda_{t}^{k, f b}
\end{array}\right] .
\end{aligned}
$$

\section{Equilibrium Asset Prices}

Given expected utilities in the previous section, the asset prices can be derived. The equilibrium asset prices for each class of securities under mild segmentation are stated in the following theorem:

Theorem 3.1. Under mild segmentation the equilibrium asset prices for each class of securities can be expressed as follows:

$$
\begin{gathered}
E_{t}\left(p_{t+1}^{d a}\right)-p_{t}^{d a}(1+r)=\alpha_{w} C_{t}\left(p_{t+1}^{d a}, V_{t+1}^{M}\right) \\
E_{t}\left(p_{t+1}^{d b}\right)-p_{t}^{d b}(1+r)=\alpha_{w} C_{t}\left(p_{t+1}^{d b}, V_{t+1}^{M}\right)-\frac{\alpha_{w}}{\alpha_{n k}} \rho_{t}^{D}
\end{gathered}
$$

$$
\begin{aligned}
& E_{t}\left(p_{t+1}^{f a}\right)-p_{t}^{f a}(1+r) \\
& =\alpha_{j k} C_{t}\left(p_{t+1}^{f a}, V_{t+1}^{M}\right)-\left(\frac{\alpha_{w} \alpha_{j k}}{\alpha_{i n}}\right)\left[\begin{array}{l}
C_{t}(d a, f a) \\
C_{t}(d a, f a)
\end{array}\right]^{\prime} \Omega_{2 t}^{-1}\left[\begin{array}{l}
C_{t}\left(p_{t+1}^{d a}, V_{t+1}^{M}\right) \\
C_{t}\left(p_{t+1}^{d b}, V_{t+1}^{M}\right)
\end{array}\right] \\
& -\left(\frac{\alpha_{j k}}{\alpha_{n}}-\frac{\alpha_{w} \alpha_{j k}}{\alpha_{i n} \alpha_{n k}}\right)\left[\begin{array}{l}
C_{t}(d a, f a) \\
C_{t}(d b, f a)
\end{array}\right]^{\prime} \Omega_{2 t}^{-1}\left[\begin{array}{l}
0 \\
\rho_{t}^{D}
\end{array}\right] \\
& E_{t}\left(p_{t+1}^{f b}\right)-p_{t}^{f b}(1+r) \\
& =\alpha_{j k} C_{t}\left(p_{t+1}^{f b}, V_{t+1}^{M}\right)-\left(\frac{\alpha_{w} \alpha_{j k}}{\alpha_{i n}}\right)\left[\begin{array}{l}
C_{t}(d a, f b) \\
C_{t}(d b, f b)
\end{array}\right]^{\prime} \Omega_{2 t}^{-1}\left[\begin{array}{l}
C_{t}\left(p_{t+1}^{d a}, V_{t+1}^{M}\right) \\
C_{t}\left(p_{t+1}^{d b}, V_{t+1}^{M}\right)
\end{array}\right] \\
& -\left(\frac{\alpha_{j k}}{\alpha_{n}}-\frac{\alpha_{w} \alpha_{j k}}{\alpha_{i n} \alpha_{n k}}\right)\left[\begin{array}{l}
C_{t}(d a, f b) \\
C_{t}(d b, f b)
\end{array}\right]^{\prime} \Omega_{2 t}^{-1}\left[\begin{array}{l}
0 \\
\rho_{t}^{D}
\end{array}\right]-\left(\frac{\alpha_{j k}}{\alpha_{k}}\right) \rho_{t}^{F},
\end{aligned}
$$

\footnotetext{
b The relaxation of the implicit assumption of similar price misperceptions by both domestic and
} foreign traders does not provide new insights and makes the analysis more cumbersome. 
where $V_{t}^{D} \equiv p_{t}^{d a}+p_{t}^{d b}$ is domestic market value, $V_{t}^{F} \equiv p_{t}^{f a}+p_{t}^{f b}$ is foreign market value, $V_{t}^{M} \equiv V_{t}^{D}+V_{t}^{F}$ is global market value, $\alpha^{i} \equiv$ coefficient of absolute risk aversion for investor $i$, and aggregate measures of risk aversion are defined as follows:

$$
\begin{aligned}
\alpha_{w} & \equiv\left(\sum_{i \in I} \frac{1}{\alpha^{i}}+\sum_{n \in N} \frac{1}{\alpha^{n}}+\sum_{j \in J} \frac{1}{\alpha^{j}}+\sum_{k \in K} \frac{1}{\alpha_{k}}\right)^{-1}, \quad \alpha_{k} \equiv\left(\sum_{k \in K} \frac{1}{\alpha^{k}}\right)^{-1}, \\
\alpha_{i n} & \equiv\left(\sum_{i \in I} \frac{1}{\alpha^{i}}+\sum_{n \in N} \frac{1}{\alpha^{n}}\right)^{-1}, \quad \alpha_{n k} \equiv\left(\sum_{n \in N} \frac{1}{\alpha^{n}}+\sum_{k \in K} \frac{1}{\alpha^{k}}\right)^{-1}, \\
\alpha_{n} & \equiv\left(\sum_{n \in N} \frac{1}{\alpha^{n}}\right)^{-1} \alpha_{i j} \equiv\left(\sum_{i \in I} \frac{1}{\alpha^{i}}+\sum_{j \in J} \frac{1}{\alpha^{j}}\right)^{-1} .
\end{aligned}
$$

Proof. See Appendix A.

Equation (3.1) in Theorem 3.1 states that the presence of noise in other asset markets will not alter the familiar past results. That is, with a one-way barrier, the domestic security without noise is priced as if the market was fully integrated, i.e. only a function of world covariance risk. Equation (3.2) is essentially identical to DSSW which shows the price for the domestic security with noise is a function of period $t$ 's misperception by noise traders. Equation (3.3) is the pricing equation for the foreign security without noise. In addition to the world covariance risk, there are two additional terms in Eq. (3.3). Both terms are related to the ability of domestic securities to replicate the foreign security without noise. These two terms will be further studied in Theorem 3.2. Similarly, Eq. (3.4) states that price of the foreign security with noise will depend on the world covariance risk, the risk related to the replication by domestic securities, and its own noise term.

The interpretation of Eq. (3.3) can be made more intuitive by expressing it in a more familiar form as stated in the following theorem. This will help us interpret the results along the lines of previous papers in the literature.

Theorem 3.2. Pricing kernel for foreign security traded without noise under mild segmentation can be expressed in the following terms:

$$
\begin{aligned}
E_{t}\left(p_{t+1}^{f a}\right)-p_{t}^{f a}(1+r)= & \alpha_{w} C_{t}\left(p_{t+1}^{f a}, V_{t+1}^{M}\right)-\left(\alpha_{j k}-\alpha_{w}\right)\left[C_{t}\left(p_{t+1}^{f a}, V_{t+1}^{F}\right)\right. \\
& \left.-C_{t}\left(p_{t+1}^{f a}, V_{t+1}^{A}\right)\right]-\left(\frac{\alpha_{j k}}{\alpha_{n}}-\frac{\alpha_{w} \alpha_{j k}}{\alpha_{i n} \alpha_{n k}}\right) \beta_{3} \rho_{t}^{D}
\end{aligned}
$$

where $\beta_{3}$ is the covariance between $p^{f a}$ and $p^{d b}$ conditional on $p^{d a}, V^{A}$ is the "adjustment" portfolio which is the portfolio of domestic securities most highly correlated with the portfolio of foreign securities. 
Proof. See Appendix B.

Theorem 3.2 states that price for the foreign security without noise is a function of (i) its covariance with the world market portfolio; (ii) the "pure" foreign market risk premium which is defined in [6] as the difference between covariance of $p^{f a}$ and $V^{F}$, and covariance of $p^{f a}$ with $V^{A}$; and (iii) a "noise spill-over" risk premium resulting from domestic noise. Notice that unlike the domestic asset without noise, the foreign asset without noise is influenced by the noise originating in the pricing of the domestic asset $p^{d b}$. This "noise spill-over" risk premium has not been documented in the previous literature. The immediate implication of which is that governments cannot shield domestic financial markets from international sources of noise by creating a one-way barrier.

A more precise analysis of the impact of noise on assets prices requires steady state solutions for prices. We assume that $\rho_{t}^{D} \sim N\left(\rho^{m D}, \sigma_{\rho D}^{2}\right), \rho_{t}^{F} \sim N\left(\rho^{m F}, \sigma_{\rho F}^{2}\right)$ and the unconditional distribution of assets prices are equal to their conditional distributions. Given these assumptions, steady state solutions implied by Theorem 3.1 for equilibrium prices can be derived by recursion.

Theorem 3.3. Under mild segmentation, the steady state equilibrium asset prices for each class of assets can be expressed as follows:

$$
\begin{aligned}
p_{t}^{d a}=\frac{d^{d a}}{r}-\frac{\alpha^{w}}{r} C_{t}\left(p_{t+1}^{d a}, V_{t+1}^{M}\right) \\
p_{t}^{d b}=\frac{d^{d b}}{r}-\frac{\alpha_{w}}{r} C_{t}\left(p_{t+1}^{d b}, V_{t+1}^{M}\right)+\frac{\alpha_{w}}{\alpha_{n k}} \cdot \frac{\left(\rho_{t}^{D}-\rho^{m D}\right)}{1+r}+\frac{\alpha_{w}}{\alpha_{n k}} \cdot \frac{\rho^{m D}}{r} \\
p_{t}^{f a}=\frac{d^{f a}}{r}-\frac{\alpha_{w}}{r} C_{t}\left(p_{t+1}^{f a}, V_{t+1}^{M}\right)-\frac{\left(\alpha_{j k}-\alpha_{w}\right)}{r} C_{t}\left(p_{t+1}^{f a}, V_{t+1}^{F}\right) \\
+\frac{\left(\alpha_{j k}-\alpha_{w}\right)}{r} C_{t}\left(p_{t+1}^{f a}, V_{t+1}^{A}\right)+\frac{A \beta_{3}\left(\rho_{t}^{D}-\rho^{m D}\right)}{1+r}+\frac{A \beta_{3}}{r} \rho^{m D} \\
p_{t}^{f b}=\frac{d^{f b}-\frac{\alpha_{w}}{r} C_{t}\left(p_{t+1}^{f b}, V_{t+1}^{M}\right)-\frac{\left(\alpha_{j k}-\alpha_{w}\right)}{r} C_{t}\left(p_{t}^{f b}, V_{t+1}^{F}\right)}{+} \\
+\frac{\left(\alpha_{j k}-\alpha_{w}\right)}{r} C_{t}\left(p_{t+1}^{f b}, V_{t+1}^{A}\right)+\frac{A \beta_{4}\left(\rho_{t}^{D}-\rho^{m D}\right)}{1+r}+\frac{A \beta_{4}}{r} \rho^{m D} \\
+\frac{\alpha_{w}\left(\rho_{t}^{F}-\rho^{m F}\right)}{\alpha_{k}(1+r)}+\frac{\alpha_{w}}{\alpha_{k} r} \rho^{m F},
\end{aligned}
$$

where $A=\left(\frac{\alpha_{j k}}{\alpha_{n}}-\frac{\alpha_{w} \alpha_{j k}}{\alpha_{i n} \alpha_{n k}}\right), \beta_{3}$ is the covariance of $p^{d b}$ and $p^{\text {fa }}$ conditional on $p^{d a}$ and $\beta_{4}$ is the covariance of $p^{d b}$ and $p^{f b}$ conditional on $p^{d a}$.

From Theorem 3.3, we can immediately assess the impact of changes in noise trader sentiment on asset prices. Equation (3.6) states that an increase in domestic noise trader bullishness, i.e. increase in $\rho_{t}^{D}$, has no effect on the domestic asset 
without noise. Equation (3.7) states that the impact of an increase in domestic noise bullishness on the domestic asset with noise is proportional to the risk aversion of all traders relative to that of noise traders, and the discount rate $r$.

From Eq. (3.8), we can assess the conditions under which the price of the foreign asset without noise may increase, decrease, or remain unchanged, given an increase in domestic noise trader bullishness. We state these conditions in the following theorem:

Theorem 3.4. Under mild segmentation and assuming international asset prices are positively correlated and all investors are equally risk adverse, an increase in domestic noise bullishness will decrease (increase) the price for the foreign asset without noise if the ratio of noise traders to total traders is higher (lower) in the foreign market than that in the domestic market.

Proof. If all assets are positively related, then $\beta_{3}$ in Eq. (3.8) is strictly positive. Hence, the sign of $A$ determines the relationship between domestic noise $\rho_{t}^{D}$ and foreign asset price $p_{t}^{f a}$. Note that $A$ reflects two characteristics: (1) the average risk aversion coefficient of each investor type, and (2) the number of investors of each investor type. Assuming investor risk preferences are identical across investor types, the sign of $A$ depends only on the measure of noise traders to rational traders. To see this, recall that

$$
\begin{aligned}
A= & \left(\frac{\alpha_{j k}}{\alpha_{n}}-\frac{\alpha_{w} \alpha_{j k}}{\alpha_{i n} \alpha_{n k}}\right)=\alpha_{w} \alpha_{j k}\left(\frac{1}{\alpha_{n} \alpha_{w}}-\frac{1}{\alpha_{i n} \alpha_{n k}}\right) \\
= & \alpha_{w} \alpha_{j k}\left\{\left(\sum_{n \in N} \frac{1}{\alpha^{n}}\right)\left(\sum_{i \in I} \frac{1}{\alpha^{i}}+\sum_{n \in N} \frac{1}{\alpha^{n}}+\sum_{j \in J} \frac{1}{\alpha^{j}}+\sum_{k \in K} \frac{1}{\alpha^{k}}\right)\right. \\
& \left.-\left(\sum_{i \in I} \frac{1}{\alpha^{i}}+\sum_{n \in N} \frac{1}{\alpha^{n}}\right)\left(\sum_{n \in N} \frac{1}{\alpha^{n}}+\sum_{k \in K} \frac{1}{\alpha^{k}}\right)\right\} \\
= & \alpha_{w} \alpha_{j k}\left(\sum_{n \in N} \frac{1}{\alpha^{n}} \sum_{j \in J} \frac{1}{\alpha^{j}}-\sum_{i \in I} \frac{1}{\alpha^{i}} \sum_{k \in K} \frac{1}{\alpha^{k}}\right) .
\end{aligned}
$$

Let $\alpha$ denote the common constant risk aversion coefficient across all investors. Then $A$ can be written as follows:

$$
A=\alpha_{w} \alpha_{j k}\left(\frac{N}{\alpha} \cdot \frac{J}{\alpha} \cdot \frac{I}{\alpha} \cdot \frac{K}{\alpha}\right) .
$$

Let $P=\frac{I}{N+I}$, i.e. the percent of domestic investors which are rational; $Q=$ $\frac{J}{J+K}$, i.e. the percent of foreign investors which are rational; $D=N+I$, i.e. the total domestic investor population; $F=J+K$, i.e. the total foreign investor population. 
Using these definitions, $A$ can be expressed as

$$
A=\alpha_{w} \alpha_{j k}\left\{\left[\frac{(1-P) D}{\alpha} \cdot \frac{Q F}{\alpha}\right]-\left[\frac{P D}{\alpha} \cdot \frac{(1-Q) F}{\alpha}\right]\right\}
$$

which can be rewritten as

$$
A=\frac{\alpha_{w} \alpha_{j k} D F}{\alpha^{2}}(Q-P) .
$$

Hence, $A<0$ is equivalent to $Q<P$. That is $A<0$ is equivalent to the ratio of noise traders to total traders is higher in the foreign market than that in the domestic market.

\section{Noise Trader Risk}

The goal of this section is to analyze the impact of noise trader risk on asset prices. Since our focus is on the noise trader risk, we will suppress fundamental risk and concentrate on noise trader risk. The impact of noise trader risk on asset prices is summarized in the following theorem.

Theorem 4.1. Under mild segmentation, steady state equilibrium asset prices arising from noise are as follows:

$$
\begin{aligned}
p_{t}^{d a} \text { (noise) }= & 0 \\
p_{t}^{d b} \text { (noise) }= & \frac{\alpha_{w}}{\alpha_{n k}} \cdot \frac{\left(\rho_{t}^{D}-\rho^{m D}\right)}{(1+r)}+\frac{\alpha_{w}}{\alpha_{n k}} \frac{\rho^{m D}}{r} \\
& -\frac{\alpha_{w}}{\alpha_{n k}} \cdot \frac{1}{r(1+r)^{2}}\left[\frac{\alpha_{w}^{2}}{\alpha_{n k}}+A \beta_{2}\right] \sigma_{\rho D}^{2} \\
p_{t}^{f a}(\text { noise })= & \frac{A \beta_{3}}{1+r}\left(\rho_{t}^{D}-\rho^{m D}\right)+\frac{A \beta_{3}}{r} \rho^{m D}-\frac{\alpha_{j k}}{r}\left[\frac{A^{2} \beta_{3}^{2}}{(1+r)^{2}}+\frac{A^{2} \beta_{3} \beta_{4}}{(1+r)^{2}}\right] \sigma_{\rho D}^{2} \\
& +\frac{\beta_{2} \alpha_{j k}-\left(1+\beta_{2}\right) \alpha_{w}}{r} \frac{A \beta_{3}}{(1+r)^{2}} \frac{\alpha_{w}}{\alpha_{n k}} \sigma_{\rho D}^{2}, \\
p_{t}^{f b}(\text { noise })= & \frac{A \beta_{4}\left(\rho_{t}^{D}-\rho^{m D}\right)}{(1+r)}+\frac{A \beta_{4}}{r} \rho^{m D}+\frac{\alpha_{j k}\left(\rho_{t}^{F}-\rho^{m F}\right)}{\alpha_{k}(1+r)}+\frac{\alpha_{j k}}{\alpha_{k} \cdot r} \rho^{m F} \\
& -\frac{\alpha_{j k}}{r}\left(\frac{A^{2} \beta_{3} \beta_{4}}{(1+r)^{2}}+\frac{A^{2} \beta_{4}^{2}}{(1+r)^{2}}\right) \sigma_{\rho D}^{2} \\
& +\frac{\beta_{2} \alpha_{j k}-\left(1+\beta_{2}\right) \alpha_{w}}{r} \frac{A \beta_{4}}{(1+r)^{2}} \frac{\alpha_{w}}{\alpha_{n k}} \sigma_{\rho D}^{2} \\
& -\frac{\alpha_{j k}}{(1+r)^{2}} \frac{\alpha_{j k}^{2}}{\alpha_{k}^{2}} \alpha_{\rho F}^{2} \cdot
\end{aligned}
$$


In order to see the impact of one-way barrier on asset pricing, let's compare Eq. (4.2) to the pricing function in DSSW (Eq. (12) in p. 710). The major difference is the influence of $\sigma_{\rho D}^{2}$ to the price. One-way barrier creates the additional term, $A \beta_{2}$. Parameter $A$ represents the risk preference. However, $\beta_{2}$ measures the ability of eligible security with noise to replicate the foreign portfolio.

Similarly, the impact of noise trader risk on the volatilities of asset prices are summarized in the following theorem.

Theorem 4.2. Under mild segmentation, the incremental volatilities of asset prices arising from the existence of noise trader are as follows:

$$
\begin{gathered}
\Delta \operatorname{Var}\left(p_{t}^{d a}\right)=0 \\
\Delta \operatorname{Var}\left(p_{t}^{d b}\right)=\left(\frac{\alpha_{w}}{\alpha_{n k}}\right)^{2} \frac{1}{(1+r)^{2}} \sigma_{\rho D}^{2}, \\
\Delta \operatorname{Var}\left(p_{t}^{f a}\right)=\left(\frac{A \beta_{3}}{1+r}\right)^{2} \sigma_{\rho D}^{2}, \\
\Delta \operatorname{Var}\left(p_{t}^{f b}\right)=\left(\frac{A \beta_{4}}{1+r}\right)^{2} \sigma_{\rho D}^{2}+\left(\frac{\alpha_{j k}}{\alpha_{k}}\right)^{2} \frac{1}{(1+r)^{2}} \sigma_{\rho F}^{2} .
\end{gathered}
$$

Equations (4.5) and (4.6) are the well-known results. Equations (4.7) and (4.8) again demonstrate the spill-over effect from domestic noise term to the volatility of foreign securities. The magnitudes of influence depends on two factors: risk preference parameter, $A$ and the ability of replication of foreign security by domestic security with noise, $\beta_{3}$ and $\beta_{4}$.

\section{Conclusion}

In this paper we incorporate noise trader's mispricing in an international setting with investment barriers. The subcases of our general model include international CAPM, international asset pricing model with investment barrier as well as domestic noise trader's pricing model. The model allows us to analyze how irrational pricing behavior affects international asset pricing across alternative market structures. In general, we find that noise traders induce an additional risk premium which can further segment international capital markets over and beyond capital barriers. This result suggests that the removal of capital barriers is not a sufficient condition to achieve integrated world markets. This result is consistent with the recent empirical evidence on the evolution of market integration.

\section{Appendix A. Proof of Theorem 3.1}

Representative investors $i, n, j$ and $k$ maximize Eqs. (2.4)-(2.7) when choosing asset demands, respectively. The corresponding first order conditions for each class 
of investors are as follows:

$$
\begin{gathered}
{\left[\begin{array}{l}
E_{t}\left(p_{t+1}^{d a}\right)-p_{t}^{d a}(1+r) \\
E_{t}\left(p_{t+1}^{d b}\right)-p_{t}^{d b}(1+r)
\end{array}\right]=\alpha^{i} \Omega_{2 t}\left[\begin{array}{l}
\lambda_{t}^{i, d a} \\
\lambda_{t}^{i, d b}
\end{array}\right], \quad i \in I} \\
{\left[\begin{array}{l}
0 \\
\rho_{t}^{D}
\end{array}\right]+\left[\begin{array}{l}
E_{t}\left(p_{t+1}^{d a}\right)-p_{t}^{d a}(1+r) \\
E_{t}\left(p_{t+1}^{d b}\right)-p_{t}^{d b}(1+r)
\end{array}\right]=\alpha^{n} \Omega_{2 t}\left[\begin{array}{l}
\lambda_{t}^{n, d a} \\
\lambda_{t}^{n, d b}
\end{array}\right], \quad n \in N} \\
{\left[\begin{array}{l}
E_{t}\left(p_{t+1}^{d a}\right)-p_{t}^{d a}(1+r) \\
E_{t}\left(p_{t+1}^{d b}\right)-p_{t}^{d b}(1+r) \\
E_{t}\left(p_{t+1}^{f a}\right)-p_{t}^{f a}(1+r) \\
E_{t}\left(p_{t+1}^{f b}\right)-p_{t}^{f b}(1+r)
\end{array}\right]=\alpha^{j} \Omega_{4 t}\left[\begin{array}{l}
\lambda_{t}^{j, d a} \\
\lambda_{t}^{j, d b} \\
\lambda_{t}^{j, f a} \\
\lambda_{t}^{j, f b}
\end{array}\right], \quad j \in J} \\
{\left[\begin{array}{l}
0 \\
\rho_{t}^{D} \\
0 \\
\rho_{t}^{F}
\end{array}\right]+\left[\begin{array}{l}
E_{t}\left(p_{t+1}^{d a}\right)-p_{t}^{d a}(1+r) \\
E_{t}\left(p_{t+1}^{d b}\right)-p_{t}^{d b}(1+r) \\
E_{t}\left(p_{t+1}^{f a}\right)-p_{t}^{f a}(1+r) \\
E_{t}\left(p_{t+1}^{f b}\right)-p_{t}^{f b}(1+r)
\end{array}\right]=\alpha^{k} \Omega_{4 t}\left[\begin{array}{l}
\lambda_{t}^{k, d a} \\
\lambda_{t}^{k, d b} \\
\lambda_{t}^{k, f a} \\
\lambda_{t}^{k, f b}
\end{array}\right], \quad k \in K .}
\end{gathered}
$$

Equilibrium prices are determined by summing over individual demands and setting aggregate asset demand equal to aggregate supply (normalize to be 1) for each security $s \in d a, d b, f a, f b$. The solution can most easily be obtained by expressing aggregate investor demand function in a common $4 \times 4$ matrix.

This requires expressing Eqs. (A.1) and (A.2), which are $2 \times 2$ matrices, into an equivalent "augmented" $4 \times 4$ matrix form. Following this procedure, Eq. (A.1) can be expressed as follows:

$$
\begin{aligned}
\Omega_{4 t}\left[\begin{array}{c}
\sum_{i \in I} \lambda_{t}^{i, d a} \\
\sum_{i \in I} \lambda_{t}^{i, d b} \\
0 \\
0
\end{array}\right]= & \sum_{i \in I} \frac{1}{\alpha^{i}}\left[\begin{array}{c}
E_{t}\left(p_{t+1}^{d a}\right)-p_{t}^{d a}(1+r) \\
E_{t}\left(p_{t+1}^{d b}\right)-p_{t}^{d b}(1+r) \\
0 \\
0
\end{array}\right] \\
+ & {\left[\begin{array}{c}
C_{t}(f a, d a) \sum_{i \in I} \lambda_{t}^{i, d a}+C_{t}(f a, d b) \sum_{i \in I} \lambda_{t}^{i, d b} \\
0 \\
C_{t}(f b, d a) \sum_{i \in I} \lambda_{t}^{i, d a}+C_{t}(f b, d b) \sum_{i \in I} \lambda_{t}^{i, d b}
\end{array}\right] }
\end{aligned}
$$


and Eq. (A.2) can be expressed as follows:

$$
\begin{aligned}
& \Omega_{4 t}\left[\begin{array}{c}
\sum_{n \in N} \lambda_{t}^{n, d a} \\
\sum_{n \in N} \lambda_{t}^{n, d b} \\
0 \\
0
\end{array}\right]=\sum_{n \in N} \frac{1}{\alpha^{n}}\left[\begin{array}{c}
E_{t}\left(p_{t+1}^{d a}\right)-p_{t}^{d a}(1+r) \\
E_{t}\left(p_{t+1}^{d b}\right)-p_{t}^{d b}(1+r) \\
0 \\
0
\end{array}\right] \\
& +\left[\begin{array}{c}
0 \\
0 \\
C_{t}(f a, d a) \sum_{n \in N} \lambda_{t}^{n, d a}+C_{t}(f a, d b) \sum_{n \in N} \lambda_{t}^{n, d b} \\
C_{t}(f b, d a) \sum_{n \in N} \lambda_{t}^{n, d a}+C_{t}(f b, d b) \sum_{n \in N} \lambda_{t}^{n, d b}
\end{array}\right]+\sum_{n \in N} \frac{1}{\alpha^{N}}\left[\begin{array}{c}
0 \\
\rho_{t}^{D} \\
0 \\
0
\end{array}\right] .
\end{aligned}
$$

Equation (A.3) after aggregating individual demands over investor $j \in J$ becomes

$$
\Omega_{4 t}\left[\begin{array}{l}
\sum_{j \in J} \lambda_{t}^{j, d a} \\
\sum_{j \in J} \lambda_{t}^{j, d b} \\
\sum_{j \in J} \lambda_{t}^{j, f a} \\
\sum_{j \in J} \lambda_{t}^{j, f b}
\end{array}\right]=\sum_{j \in J} \frac{1}{\alpha^{j}}\left[\begin{array}{l}
E_{t}\left(p_{t+1}^{d a}\right)-p_{t}^{d a}(1+r) \\
E_{t}\left(p_{t+1}^{d b}\right)-p_{t}^{d b}(1+r) \\
E_{t}\left(p_{t+1}^{f a}\right)-p_{t}^{f a}(1+r) \\
E_{t}\left(p_{t+1}^{f b}\right)-p_{t}^{f b}(1+r)
\end{array}\right] .
$$

Similarly, Eq. (A.4) after aggregating individual demand over investor $k \in K$ becomes

$$
\Omega_{4 t}\left[\begin{array}{l}
\sum_{k \in K} \lambda_{t}^{k, d a} \\
\sum_{k \in K} \lambda_{t}^{k, d b} \\
\sum_{k \in K} \lambda_{t}^{k, f a} \\
\sum_{k \in K} \lambda_{t}^{k, f b}
\end{array}\right]=\sum_{k \in K}\left(\frac{1}{\alpha^{k}}\right)\left[\begin{array}{c}
\lambda_{t}^{k, d a} \\
\lambda_{t}^{k, d b} \\
\lambda_{t}^{k, f a} \\
\lambda_{t}^{k, f b}
\end{array}\right]+\sum_{k \in K}\left(\frac{1}{\alpha^{k}}\right)\left[\begin{array}{c}
0 \\
\rho_{t}^{D} \\
0 \\
\rho_{t}^{F}
\end{array}\right] .
$$

Summing up Eqs. (A.5), (A.6), (A.7) and (A.8), as well as recognizing that market clearing condition requires that total demand for each security must be 
equal to total supply, we have the following expression:

$$
\begin{aligned}
\Omega_{4 t}\left[\begin{array}{l}
1 \\
1 \\
1 \\
1
\end{array}\right]= & {\left[\begin{array}{l}
\alpha_{w}^{-1} E_{t}\left(p_{t+1}^{d a}\right)-\alpha_{w}^{-1} p_{t}^{d a}(1+r) \\
\alpha_{w}^{-1} E_{t}\left(p_{t+1}^{d b}\right)-\alpha_{w}^{-1} p_{t}^{d b}(1+r) \\
\alpha_{j k}^{-1} E_{t}\left(p_{t+1}^{f a}\right)-\alpha_{j k}^{-1} p_{t}^{f a}(1+r) \\
\alpha_{j k}^{-1} E_{t}\left(p_{t+1}^{f b}\right)-\alpha_{j k}^{-1} p_{t}^{f b}(1+r)
\end{array}\right]+\left[\begin{array}{c}
0 \\
\alpha_{n k}^{-1} \rho_{t}^{D} \\
0 \\
\alpha_{k}^{-1} \rho_{t}^{F}
\end{array}\right] } \\
& +\left[\begin{array}{c}
0 \\
0 \\
C_{t}(f a, d a)\left(\sum_{i \in I} \lambda_{t}^{i, d a}+\sum_{n \in N} \lambda_{t}^{n, d a}\right)+C_{t}(f a, d b)\left(\sum_{i \in I} \lambda_{t}^{i, d b}+\sum_{n \in N} \lambda_{t}^{n, d b}\right) \\
C_{t}(f b, d a)\left(\sum_{i \in I} \lambda_{t}^{i, d a}+\sum_{n \in N} \lambda_{t}^{n, d a}\right)+C_{t}(f b, d b)\left(\sum_{i \in I} \lambda_{t}^{i, d b}+\sum_{n \in N} \lambda_{t}^{n, d b}\right)
\end{array}\right] .
\end{aligned}
$$

The pricing kernel for the domestic security without noise can be easily obtained as the solution to the first row of Eq. (A.9). Hence, we have

$$
E_{t}\left(p_{t+1}^{d a}\right)-p_{t}^{d a}(1+r)=\alpha_{w} C_{t}\left(p_{t+1}^{d a}, V_{t+1}^{M}\right) .
$$

This is Eq. (3.1) in Theorem 3.1.

Similarly, solving for the second row of Eq. (A.9), we have the pricing kernel for the domestic security with noise:

$$
E_{t}\left(p_{t+1}^{d b}\right)-p_{t}^{d b}(1+r)=\alpha_{w} C_{t}\left(p_{t+1}^{d b}, V_{t+1}^{M}\right)-\frac{\alpha_{w}}{\alpha_{n k}} \rho_{t}^{D} .
$$

This is Eq. (3.2).

To solve the pricing kernels for $d a$ and $d b$, we derive the aggregate demand function for investors $s \in I, N$ for securities $d a$ and $d b$ from Eqs. (A.1) and (A.2) as follows:

$$
\left[\begin{array}{c}
\sum_{s \in I \& N} \lambda_{t}^{i, d a} \\
\sum_{i \in I \& N} \lambda_{t}^{i, d b}
\end{array}\right]=\alpha_{i n}^{-1} \Omega_{2}^{-1}\left[\begin{array}{c}
E_{t}\left(p_{t+1}^{d a}\right)-p_{t}^{d a}(1+r) \\
E_{t}\left(p_{t+1}^{d b}\right)-p_{t}^{d b}(1+r)
\end{array}\right]+\alpha_{n}^{-1} \Omega_{2}^{-1}\left[\begin{array}{c}
0 \\
\rho_{t}^{D}
\end{array}\right] .
$$

Substituting Eq. (A.12) into Eq. (A.9) and solving for the third row, we have the following pricing kernel for the foreign asset without noise:

$$
\begin{aligned}
E_{t}\left(p_{t+1}^{f a}\right) & -p_{t}^{f a}(1+r) \\
= & \alpha_{j k} C_{t}\left(p_{t+1}^{f a}, V_{t+1}^{M}\right)-\left(\frac{\alpha_{w} \alpha_{j k}}{\alpha_{i n}}\right)\left[\begin{array}{c}
C_{t}(d a, f a) \\
C_{t}(d b, f a)
\end{array}\right]^{\prime} \Omega_{2 t}^{-1}\left[\begin{array}{l}
C_{t}\left(p_{t+1}^{d a}, V_{t+1}^{M}\right) \\
C_{t}\left(p_{t+1}^{d b}, V_{t+1}^{M}\right)
\end{array}\right] \\
& -\left(\frac{\alpha_{j k}}{\alpha_{n}}-\frac{\alpha_{w} \alpha_{j k}}{\alpha_{i n} \alpha_{n k}}\right)\left[\begin{array}{l}
C_{t}(d a, f a) \\
C_{t}(d b, f a)
\end{array}\right]^{\prime} \Omega_{2 t}^{-1}\left[\begin{array}{l}
0 \\
\rho_{t}^{D}
\end{array}\right] .
\end{aligned}
$$

This is Eq. (3.3) in Theorem 3.1. 
Similarly, solving the fourth row of Eq. (A.9) after substituting in Eq. (A.12), we have the following pricing kernel for the foreign asset with noise:

$$
\begin{aligned}
E_{t}\left(p_{t+1}^{f b}\right) & -p_{t}^{f b}(1+r) \\
= & \alpha_{j k} C_{t}\left(p_{t+1}^{f b}, V_{t+1}^{M}\right)-\left(\frac{\alpha_{w} \alpha_{j k}}{\alpha_{i n}}\right)\left[\begin{array}{c}
C_{t}(d a, f b) \\
C_{t}(d a, f b)
\end{array}\right]^{\prime} \Omega_{2 t}^{-1}\left[\begin{array}{l}
C_{t}\left(p_{t+1}^{d a}, V_{t+1}^{M}\right) \\
C_{t}\left(p_{t+1}^{d b}, V_{t+1}^{M}\right)
\end{array}\right] \\
& -\left(\frac{\alpha_{j k}}{\alpha_{n}}-\frac{\alpha_{w} \alpha_{j k}}{\alpha_{i n} \alpha_{n k}}\right)\left[\begin{array}{c}
C_{t}(d a, f a) \\
C_{t}(d b, f a)
\end{array}\right]^{\prime} \Omega_{2 t}^{-1}\left[\begin{array}{l}
0 \\
\rho_{t}^{D}
\end{array}\right]-\left(\frac{\alpha_{j k}}{\alpha_{k}}\right) \rho_{t}^{F} .
\end{aligned}
$$

This is Eq. (3.4) in text.

\section{Appendix B. Proof of Theorem 3.2}

We first make use of the following fact:

$$
\frac{\alpha_{w} \alpha_{j k}}{\alpha_{i n}}=\alpha_{j k}-\alpha_{w}>0 .
$$

Substituting Eq. (B.1) into Eq. (3.3) and noting that $V_{t+1}^{M}=V_{t+1}^{D}+V_{t+1}^{F}$, we obtain:

$$
\begin{aligned}
E_{t}\left(p_{t+1}^{f a}\right)-p_{t}^{f a}(1+r)= & {\left[\left(\alpha_{j k}-\alpha_{w}\right)+\alpha_{w}\right] C_{t}\left(p_{t+1}^{f a}, V_{t+1}^{M}\right) } \\
& -\left(\alpha_{j k}-\alpha_{w}\right)\left[\begin{array}{c}
C_{t}(d a, f a) \\
C_{t}(d b, f a)
\end{array}\right]^{\prime} \Omega_{2 t}^{-1}\left[\begin{array}{l}
C_{t}\left(p_{t+1}^{f a}, V_{t+1}^{D}\right) \\
C_{t}\left(p_{t+1}^{f b}, V_{t+1}^{D}\right)
\end{array}\right] \\
& -\left(\alpha_{j k}-\alpha_{w}\right)\left[\begin{array}{c}
C_{t}(d a, f a) \\
C_{t}(d b, f a)
\end{array}\right]^{\prime} \Omega_{2 t}^{-1}\left[\begin{array}{l}
C_{t}\left(p_{t+1}^{f a}, V_{t+1}^{F}\right) \\
C_{t}\left(p_{t+1}^{f b}, V_{t+1}^{F}\right)
\end{array}\right] \\
& -\left(\frac{\alpha_{j k}}{\alpha_{n}}-\frac{\alpha_{w} \alpha_{j k}}{\alpha_{i n} \alpha_{n k}}\right)\left[\begin{array}{l}
C_{t}(d a, f a) \\
C_{t}(d b, f a)
\end{array}\right]^{\prime} \Omega_{2 t}^{-1}\left[\begin{array}{l}
0 \\
\rho_{t}^{D}
\end{array}\right] .
\end{aligned}
$$

Again noting that $V_{t+1}^{M}=V_{t+1}^{D}+V_{t+1}^{F}$, we obtain:

$$
\begin{aligned}
E_{t}\left(p_{t+1}^{f a}\right)-p_{t}^{f a}(1+r)= & \alpha_{w} C_{t}\left(p_{t+1}^{f a}, V_{t+1}^{M}\right)+\left(\alpha_{j k}-\alpha_{w}\right) C_{t}\left(p_{t+1}^{f a}, V_{t+1}^{F}\right)+\left(\alpha_{j k}-\alpha_{w}\right) \\
& \times\left\{C_{t}\left(p_{t+1}^{f a}, V_{t+1}^{D}\right)-\left[\begin{array}{l}
C_{t}(d a, f a) \\
C_{t}(d b, f a)
\end{array}\right]^{\prime} \Omega_{2 t}^{-1}\left[\begin{array}{c}
C_{t}\left(p_{t+1}^{f a}, V_{t+1}^{D}\right) \\
C_{t}\left(p_{t+1}^{f b}, V_{t+1}^{D}\right)
\end{array}\right]\right\} \\
& -\left(\alpha_{j k}-\alpha_{w}\right)\left[\begin{array}{l}
C_{t}(d a, f a) \\
C_{t}(d b, f a)
\end{array}\right]^{\prime} \Omega_{2 t}^{-1}\left[\begin{array}{l}
C_{t}\left(p_{t+1}^{f a}, V_{t+1}^{F}\right) \\
C_{t}\left(p_{t+1}^{f b}, V_{t+1}^{F}\right)
\end{array}\right] \\
& -\left(\frac{\alpha_{j k}}{\alpha_{n}}-\frac{\alpha_{w} \alpha_{j k}}{\alpha_{i n} \alpha_{n k}}\right)\left[\begin{array}{l}
C_{t}(d a, f a) \\
C_{t}(d b, f a)
\end{array}\right]^{\prime} \Omega_{2 t}^{-1}\left[\begin{array}{l}
0 \\
\rho_{t}^{D}
\end{array}\right] .
\end{aligned}
$$


To interpret the third and fourth terms of Eq. (B.3), consider the following projection of $V^{F}$ on $p^{d a}$ and $p^{d b}$ :

$$
V^{F}=\beta_{1} p^{d a}+\beta_{2} p^{d b}+e .
$$

Define the adjustment portfolio $V^{A}$ as the fitted values of Eq. (B.4):

$$
V^{F}=\beta_{1} p^{d a}+\beta_{2} p^{d b} .
$$

Covariance between $V^{A}$ and $p^{f a}$ can be expressed as:

$$
\begin{aligned}
\operatorname{Cov}_{t}\left(p_{t+1}^{f a}, V_{T+1}^{A}\right) & =\operatorname{Cov}_{t}\left(p_{t+1}^{f a}, \beta_{1}\left(p_{t+1}^{d a}\right)+\beta_{2}\left(p_{t+1}^{d b}\right)\right) \\
& =\beta_{1} \operatorname{Cov}_{t}\left(p_{t+1}^{f a}, p_{t+1}^{d a}\right)+\beta_{2} \operatorname{Cov}_{t}\left(p_{t+1}^{f a}, p_{t+1}^{d b}\right) \\
& =\left[\begin{array}{l}
\operatorname{Cov}_{t}\left(p_{t+1}^{f a}, p_{t+1}^{d a}\right) \\
\operatorname{Cov}_{t}\left(p_{t+1}^{f a}, p_{t+1}^{d b}\right)
\end{array}\right]^{\prime}\left[\begin{array}{l}
\beta_{1} \\
\beta_{2}
\end{array}\right] \\
& =\left[\begin{array}{l}
C_{t}(f a, d a) \\
C_{t}(f a, d b)
\end{array}\right]^{\prime} \Omega_{2 t}^{-1}\left[\begin{array}{l}
C_{t}\left(p_{t+1}^{d a}\right), V_{t+1}^{F} \\
C_{t}\left(p_{t+1}^{d b}\right), V_{t+1}^{F}
\end{array}\right] .
\end{aligned}
$$

Similarly,

$$
\operatorname{Cov}_{t}\left(p_{t+1}^{f a}, V_{T+1}^{D}\right)=\left[\begin{array}{l}
C_{t}(f a, d a) \\
C_{t}(f a, d b)
\end{array}\right]^{\prime} \Omega_{2 t}^{-1}\left[\begin{array}{l}
C_{t}\left(p_{t+1}^{d a}\right), V_{t+1}^{D} \\
C_{t}\left(p_{t+1}^{d b}\right), V_{t+1}^{D}
\end{array}\right] .
$$

Here, we made use of the fact that the linear projection of $V^{D}$ on its components $p^{d a}$ and $p^{d b}$ is just itself. Finally, we consider the following multiple repression:

$$
p^{f a}=\beta p^{d a}+\beta_{3} p^{d b}+\varepsilon
$$

and note that

$$
\beta_{3} \rho_{t}^{D}=\left[\begin{array}{c}
C_{t}(d a, f a) \\
C_{t}(d a, f b)
\end{array}\right]^{\prime} \Omega_{2 t}^{-1}\left[\begin{array}{c}
0 \\
\rho_{t}^{D}
\end{array}\right] .
$$

Substituting Eqs. (B.9), (B.10) and (B.11) into Eq. (B.3), we obtain Eq. (3.5).

\section{Acknowledgment}

M.-W. Hung thanks NSC for financial support.

\section{References}

[1] S. Basak, An intertemporal model of international capital market segmentation, J. Financial and Quantitative Analysis 31 (1996) 161-188.

[2] G. Bekaert and C. Harvey, Time-varying world market integration, J. Finance 50 (1995) 403-444. 
[3] J. B. DeLong, A. Shleifer, L. H. Summers and R. Waldmann, Noise trader risk in financial markets, J. Political Economy 98 (1990) 703-738.

[4] V. Errunza and E. Losq, International asset pricing under mild segmentation and segmentation hypothesis, J. Finance 40 (1985) 105-124.

[5] V. Errunza, K. Hogan and M. Hung, Home-made diversification, gains from international diversification and market integration, working paper, McGill Univ. (1996).

[6] C. Eun and S. Janakiramanan, A model of international asset pricing with a constraint on the foreign equity ownership, J. Finance 41 (1986) 897-914.

[7] C. Harvey, The world price of covariance risk, J. Finance 46 (1991) 111-157.

[8] P. Padmanabhan, Investment barriers and international asset pricing, Rev. Quantitative Finance and Accounting 2 (1992) 299-319.

[9] R. Stulz, On the effects of barriers to international investment, J. Finance 36 (1981) 923-934. 